\title{
Online Learning Meets Mixed-Reality Immersive Spaces: Result Increased Learning
}

\author{
Lin Carver, Ph. D. \\ Associate Professor, Saint Leo University \\ 33701 State Road 52, MC2005 \\ Saint Leo, FL 33574 \\ Holly Atkins, Ph. D. \\ Associate Professor, Saint Leo University \\ 33701 State Road 52, MC2005 \\ Saint Leo, FL 33574
}

\begin{abstract}
Online learning in higher education is no longer an anomaly. The majority of American college courses include some digital components, and fully online degree programs are ubiquitous throughout all disciplines. The delivery format of online courses is particularly in line with the needs of the adult learner who often faces challenges of balancing work, family, and graduate coursework. While flexibility is an appealing aspect to online courses, the question of how to engage learners in meaningful, collaborative knowledge-creation remains. Innovative developments in technology provide support in the search for the answer. A small, private university in the southeastern United States employed the use of mixed-reality simulations to increase student-to-student engagement and to encourage the transfer of skills between the classroom and the real-world setting. Students enrolled in an introductory qualitative research course applied the theoretical concepts foundational to conducting effective focus groups through the use of a simulated middle school classroom environment with six student participants (avatars). Using a web conferencing tool that enabled all participants (and the course instructor) to see and be seen during individual focus group sessions, collaborative, shared experiences became the central feature of what students described as an important experience. Innovative tools such as mixed-reality immersive environments provide faculty from a range of disciplines to engage online students in experiences in which the online platform supports and extends meaningful learning.
\end{abstract}

Keywords: Online learning, Higher education, Avatars, Mixed-reality

\section{INTRODUCTION}

As technological options expand, online education continues to play an even more significant role in higher education. This expansion is especially true among adult learners at the university level (Jo, Kim, \& Yoon, 2015). In fact, Ciabocchi, Ginsberg and Picciano [4] determined that the majority of American college courses include some digital components. These components ranged from fully online course to those where a portion were Web enhanced through the use of webpages and videos. Consequently in most higher education courses, digitally enhanced learning has become an integral part of instructional delivery.

Although exact figures range depending on how "online" is defined, Allen and Seaman [1] reported that there were between 5.5 and 7 million higher education students enrolled in at least one online course. This figure represents more than a 100\% increase from the total they identified just six years previously [1]. Although both graduate and undergraduate course are 
being offered online, graduate students have found this online format to be particularly advantageous because of reduced time constraints caused by travel, allowing adult learners a more flexible learning schedule that they can arrange around other responsibilities [14].

Studies comparing online learning and face-to-face instruction revealed that research since 1998 has recorded better learning outcomes from online courses than from face-to-face courses [16]. Zhao et al.'s findings suggested that the technological advances which enhanced two-way interaction might be promoting this online advantage. Means, Toyama, Murphy, Bakia, and Jones [11] in their analysis of 56 rigorous studies of online education found that learners in online settings significantly outperformed their peers in face-to-face settings in the use of metacognitive strategies, including self-reflection, self-explanation, and self-monitoring.

\section{Problem}

At a small, private university in the southeastern United States graduate programs are offered completely online. During one of the graduate course, Introduction to Qualitative Research, students learn to conduct focus groups and analyze the data. Learning about qualitative research can be challenging, but it is particularly difficult when the information is presented in an online format. The traditional asynchronous online environment does not allow students the opportunity to watch others conduct research. Videos can help to bridge this gap, but students are not able to interact with the videos or try out newly learned practices or strategies in a safe setting. Consequently, researchers were interested in determining whether online digital resources could be used to expand students' understanding and ability to conduct qualitative focus group research. Typical online digital resources do not allow for realistic, immersive simulations. The goal of mixed-reality simulations is to encourage the transfer of skills between the classroom and the real world setting. The mixed-reality environment provides multiple users real time active learning options [3]. Since the use of the mixed-reality integrated learning environment (MILE) is just emerging [8]; [10]; [15], it is in need of empirical research on its design, implementation, and educational effectiveness. In this study, we examined the design and application of a mixed-reality integrated learning environment using a virtual reality learning platform that integrates a sensorimotor interface into the online graduate programs. Conducting research is a complex problem solving task that requires contextualized and adaptive implementation of content representation and interpersonal interaction [9] so the content of the class seemed well matched to the mixed reality environment.

\section{Technology Enhanced Options}

After investigating the mixed-reality learning environments available, the researchers decided to implement Mursion software in a synchronous online setting. Graduate students would meet in a Zoom room at a specific pre-identified time. This would allow all students access to the Mursion virtual, immersive training simulator program that uses a combination of artificial intelligence avatars and live actors to deliver the synchronous scenarios. These scenarios were initially designed by Mursion to support pre-service teachers in handling challenging classroom situations. However, these scenarios have been expanded to numerous other settings and environments. This program was of particular interest to the researchers because studies have shown that "simulations are more effective than other instructional methods, because they simultaneously engage trainees' emotional and cognitive process" [12]. Mursion offered the researchers the added benefit of being a live, real-time simulation that is supported by a live actor. The simulation specialist playing the roles of the avatars was able to interact with the graduate students during the Mursion session and could also hear the betweensession conversations among the graduate student participants and the researchers. This 
knowledge enabled the simulation specialist to adapt the session to the needs of the students and the researchers.

The first step to incorporating Mursion into the online classroom was for the researchers to select the desired environmental setting. The researchers selected a classroom of about half a dozen middle school age avatars for this focus group experience. The researchers determined the experience would focus on middle school students' perceptions about technology usage. Next, the content information and session specifications were conveyed to the simulation specialist who would be controlling the motions and the conversation of the avatars during the session. This information is important because it helps the simulation specialist to more effectively construct the desired environment. The more specific the researcher or instructor can be, the more realistic the environment that can be created. The simulation specialist needs to know the desired previous experiences of the avatars, the persona the avatars could adapt, their content knowledge, and their level of resistance or compliance.

In this case, the avatars were to be middle school students who had experiences with iPads in school, but no other specific content knowledge was necessary by the simulation specialist. The graduate students engaging in the simulation experience were all currently classroom teachers, so the researchers determined that while classroom management was not a skill to be addressed as the focus of the planned session, the avatars needed to react as typical middle school students. A behavior setting of moderate was determined to be appropriate to support the creation of a real world experience for these participants.

\section{METHODOLOGY}

Within the structure of the 8-week graduate courses, students have the opportunity to interact with the instructor during one session a week that occurs synchronously through a program within the Learning Management System. The typical live session from one week was replaced with the Mursion session. Before the designated Mursion session, students constructed a focus group interview guide. At the agreed upon time, the participants connected with the Mursion environment by accessing the designed Zoom room. Through the use of the graduate students' computer cameras and microphones, each participant could interact directly with the avatars, and view the interactions between their peers and the avatars. One at a time, students had the opportunity to facilitate the focus group of middle grades avatars using their interview guide, respond to avatars' comments, and collect the appropriate data.

There were some features of the simulation that would not possible in a real life. Students could stop during the process if desired to regroup and elicit direction from peers or the instructor. After the session, time was provided to debrief. Through collaborative, reflective conversations facilitated by the researchers, students commented on the responses from the avatars, as well as the types of questioning approaches that elicited the richest responses. Then the next student conducted their focus group. This allowed all participants to learn from the experiences of others. During the session, the interactions between the graduate students and the avatars were recorded for ease of transcription. One participant compared the experience to "having a conversation or teaching a small group of students."

\section{Data}

Qualitative data was collected from the instructors and from the ten graduate students who participated in the simulation. Each participate journaled about the experience. The researchers independently analyzed the teachers' qualitative reflective journals for emerging themes. The data were then transcribed, described, classified (open and axial coding methods) and interpreted forming the data analysis process. Using open coding methodology, the 
researchers read through the qualitative, narrative data several times to create "chunks" of data seeking meaning that emerged from the data. The researchers also used an inductive reasoning process to generate themes and ideas and axial coding methodology to identify relationships from among themes. A deductive process to confirm or negate ideas or hypotheses was not utilized.

Each researcher coded the data and reviewed it for inter-rater reliability. During this process, the researchers debriefed to identify any variations in coding and coexistent themes. Following the inter-rater reliability check, the researchers finalized the data results in overarching themes leading to recommendations. Data interpretation allowed the researchers to theorize toward developing patterns and meanings or to "make sense" of the data. Using an analytic inductive reasoning process, data coding and concomitant interpretation, the researchers were able to: determine the common themes that emerged from the data [13], test the data for convergence, or identify how the data did not make connections with themes or categories or align with the research questions, identify deviations from the common themes and, when possible, to provide explanations of the deviations, and identify the stories or narrative enquiry that emerged from the data analysis to make appropriate recommendations. Data analysis and interpretation provided the structure for the ensuing results, analysis, and recommendations. Inter-rater reliability was evident in the themes identified. In the reflective journals both positive themes and barriers were apparent.

\section{Instructor Observations}

Instructors were given the opportunity to reflect on the Mursion session. Then through semistructured interviews between the instructors and the researchers, instructors identified three distinct advantages to the Mursion sessions as opposed to the use of video within the online course. Three themes developed: risk free environment, collaboration within a shared experience increased engagement and application, and immediate feedback. These aligned with the benefits identified by Eschenbrenner, Nah, and Siau [7].

\section{Collaboration within a Shared Experience}

Instructors observed that if this focus group had occurred in the field in the typical manner, the student would have had to describe what happened and then ask how it should have been handled. Using the standard practice of each individual conducting his own focus group, support is limited by what the student's memory and the teacher's understanding of the setting being described. With the Mursion experience, the situation is shared with peers while the faculty member is guiding the experience. Several students could engage with the avatars, as well as provide the students with opportunities to see and experience multiple different types of interactions. Candidates had the opportunity to request immediate support or suggestions from peers. This support allows the students to apply learning gained through collaboration with peers. This shared experience provides significant opportunities for reflection, support, and learning [2].

\section{Increased Engagement and Application}

Instructors observed that more informative and positive focus group interactions occurred within just short time frames, often less than 5 minutes of student to avatar interactions. De Borst and Gelder [6] found that when working with avatars people may perceive and react as if they were interacting with humans. Research shows that brain activity is recorded in regions of the brain relating to emotion and interpersonal experience. De Borst and Gelder [6] determined that the use of avatars in simulating social situations directly affects social behavior. The perception that students are interacting with humans is dependent on the approach of those facilitating the sessions. At no time during the sessions did facilitators refer 
to the avatars as "avatars," but rather, as students - and by their individual names. This helped to create a suspension of disbelieve that is critical in enabling the participants to enter this virtual environment with the mindset that they are entering an authentic classroom, engaging with authentic students, in authentic learning experiences.

\section{Immediate Feedback}

The feedback received on the work with the avatar was immediate. The instructors reported that the "pause classroom" feature was particularly valuable. If the student had concerns, the student could say, "Pause classroom" and the action would stop while the student regrouped or asked the instructor and peers for suggestions. The student then considered the feedback and when ready said, "Resume classroom." This is very different from what happens in the real world. In the typical practice, any feedback provided by the instructor or resulting from student self-reflection would not be able to be immediately applied since real life cannot be stopped to allow for a redo. During the Mursion session, the student had the opportunity to apply the feedback and determine its immediate results. This was a feature that could not have happen in real life. Students are not able to stop a focus group in the middle and start over, but with the Mursion technology they could. Culver, Landry, Mogensen, and Young [5] stressed the importance of immediate feedback in student learning especially in the digital environment.

\section{Students' Observations}

Students' reflective journals provided the second data source. After the Mursion session, students journaled about their experience. These journal entries were submitted online and were analyzed using the same method as the instructors' interviews. Axial and open coding methodologies were used to analyze and identify convergent and divergent themes. The qualitative data was coded individually by each researcher and then examined to determine inter-rater reliability. Using this process, four themes emerged: the benefits of the simulation process, characteristics of the avatars, collaboration within a shared experience, and principles related to group dynamics. All qualitative data was corroborated and triangulated to ensure the validity of the identified themes. Interestingly, the students' themes were divergent from the instructors' themes. Only one theme appeared in both the instructors and the graduate students' responses.

\section{Benefits of the Simulation Process}

Graduate students indicated that they had looked forward to this opportunity and it had exceeded their expectations. They specifically commented on the element of fun with the simulation. This is not an observation shared by the faculty. Three students' comments captured the tone of the observations about the Mursion experience.

One student stated, "This was probably the most fun I have had in this program since it started. I got so tickled by the students. This was so close to a real-life experience."

Students were amazed at the clarity of the video within the program and with how much of their environment the avatar was able to see. Another commented, "Interviewing avatars is not something I would have ever thought that I would do. However when the students asked me about the pictures on my wall- I realized it was very life-like."

A third commented on the value of the experience. "It is a learning experience that I will always cherish." 


\section{Characteristics of the Avatars}

Students originally thought that each avatar would be the same. They were amazed at the avatars life-like qualities, but that each one was distinctly different. The graduate students found that they related to each of the avatars as though they were indeed individual middle school students. Students felt the need to discuss each avatar individually because no 2 avatars reacted in the same way. Students expressed amazement at how life-like the avatars were in their motions and conversations. Candidates found that they were able to suspend reality momentarily and deal with the avatars as though they were actual middle school students, even though intellectually candidates knew they were not.

This is one of the critical roles the researchers played. Immediately when students logged in and the session began, researchers ignored the nervous laughter that is typical when students first see the avatars. The Mursion session is perceived as a new experience, but when facilitators help move the students toward regarding the avatars as authentic middle grades students, the nervous laughter abates and the classroom teachers respond as teacherprofessionals. Comments by the participants indicate the success of that process of moving from simulated environment to authentic learning experience:

One student stated, "I think I actually know these students. I could picture my students and they would answer the same way."

Another student marveled, "They each had their own personalities."

Students were impressed with the variety within the avatars. "They were just like real kids, some spoke a lot and were quick to answer, and others you had to drag information out of or call on them."

When discussing the avatars students referred to them by name. "Ethan always had an answer and Jasmine usually followed. Savannah seemed more thoughtful but gave good feedback. If she was rushed, she tended to shut down. Dev and Ava rarely volunteered anything."

\section{Collaboration within a Shared Experience}

The students were amazed that even though they were online, the avatars were able to view everything that was occurring in the graduate students' environments. During the session the avatars commented even commented on the candidates' attire or room decorations. While seemingly a minor point, this facilitated the authenticity of the experience, leading to participants' sense of this being a human to human interaction. Observing others played a very important role in this learning experience, too. The work of researchers is usually conducted in isolation, with no opportunity for the novice researcher to learn through observing others. Student participants noted the behaviors of their peers and learning gained from this observation:

One student observed, "The style of each person was different and influenced the focus group discussion."

By watching others the students developed a better understanding of their role in the focus group. One student summed it up this way. "How you ask questions was just as important as the questions. Although the questions were the same, the presentation of the questions seem to impact the responses given."

A third student further expanded on the role of interaction in the focus group. "Variations occurred in the ways in which we expanded on the responses. As interviewers we need to be 
aware of what messages we are sending to our interviewees because this can impact how they respond."

Students also observed the importance of wait time. "Sometimes the students were trying to respond, but the interviewer kept questioning or trying to clarify over their responses so what the student was saying ended up being lost."

\section{Principles Related to Group Dynamics}

Through the experience, the graduate students also learned a great deal about group dynamics, an important factor in focus groups. As a result, the student participants understood the value of focus groups as a rich form of qualitative data. One student commented, "It was great to actually try an interview with a group like this before having to do one with real people." Simulated environments such as Mursion provide this sandbox experience for students in the process of attaining skills such as conducting effective focus groups.

One student observed, "The avatars were relating their answers to the other students' comments."

Another student observed the impact of the age group on the responses. "The middle-grades avatars definitely do not elaborate as much as adults without specific prompting."

A third student learned about the role of the facilitator in a focus group. "Interviewers needed to not spend too much time with one student as a few of the students in the group became bored."

\section{Next steps}

Although the themes generated were different, both students and instructors found the experience to be beneficial. Consequently, the researchers will continue to ask where else a shared experience with the opportunity to practice and hone skills with immediate feedback can be woven throughout our education programs and beyond. Mursion offers adult avatars with scenarios for students in the Educational Leadership program to engage in challenging encounters with parents or staff. With the development of an avatar, Franklin, who has an intellectual disability, students in our Exceptional Student Education program can experience the efficacy of accommodations to support student learning. Online social work students participate in scenarios including small group therapy sessions. Criminal justice students participate in scenarios focusing on jury selection. Marketing students hone their sales skills, applying foundational principles learned in class to simulated real-world environments.

We question, too, how we can engage our students in collaborative explorations of the challenging topics such as bias. The avatars are diverse in terms of race and gender. How can self and collaborative reflections on the nature of interactions with avatars provide a space to discuss the impact of bias in those interactions? In this way the use of simulations moves beyond honing of skills, to critical examination of the deeper issues impacting the work of our students. Our next steps are guided by our questions always present in our programs - how can we not only prepare our students to participate in their work environments, but also how can we prepare them to be leaders, and agents of change within those environments. As observed by Eschenbrenner, Nah, and Siau [7] "Virtual worlds are proving to provide unique educational experiences, with its potential only at the cusp of being explored" (p. 91). 


\section{References}

Allen, E. \& Seaman, J. (2010). Learning on demand: Online education in the United States 2009. Needham, MA: Sloan Consortium.

Boud, D., Keogh, R., \& Walker, D. (2005). Reflection: Turning experiences into learning. Retrieved from file://D:/Word\%20Docs/Research\%20IRBs\%20Projects/Research\%20Mursion/shared\%20experiences.pdf

Cheng, Y., \& Wang, S. H. (2011). Applying a 3D virtual learning environment to facilitate student's application ability in the case of marketing. Computers in Human Behavior, 27(1), 576e584

Ciabocchi, E., Ginsberg, A., \& Piacciano, A. (2016). A study of faculty governance leaders' perception of online and blended learning. Online Learning, 20(3), 53-73.

Culver, D., Landry, B., Mogensen, M. \& Young, P. (2016). Does timeliness of feedback affect student learning? Retrieved from https://www.usma.edu/cfe/Literature/Culver-Landry-Mogensen-Young_16.pdf

De Borst, A. W. \& de Gelder, B. (2015). Is it the real deal? Perceptions of virtual characters versus humans: An affective cognitive neuroscience perspective. Retrieved from https://www.ncbi.nlm.nih.gov/pmc/articles/PMC4428060/

Eschenbrenner, B., Nah,F. F., \& Siau, K. (2008). 3-D virtual worlds in education: Applications, benefits, issues, and opportunities, Journal of Database Management, 19(4), p. 95-98.

Hayes, A. T., Hardin, S. E., \& Hughes, C. E. (2013). Perceived presence's role on learning outcomes in a mixed reality classroom of simulated students. In R. Shumaker (Ed.), Virtual, augmented and mixed reality. Systems and Applications (pp. 142e151). Springer Berlin Heidelberg.Jo, I., Kim, D., \& Yoon, M. (2015). Constructing proxy variables to measure adult learners' time management strategies in LMS. Educational Technology \& Society, 18(3), 214-225

Ke, Lee, \& Xu, (2016). Teaching training in a mixed-reality integrated learning environment, Computers in Human Behavior, 62, 212-220.

Liarokapis, F., \& Anderson, E. (2010). Using augmented reality as a medium to assist teaching in higher education. In Proceedings of the 31st annual conference of the European association for computer graphics (Eurographics 2010) (pp. 9-16). Norrkoping, Sweden.

Means, B., Toyanna, Y., Murphy, R., Bakia, M., \& Jones, K. (2009). Evaluation of evidence-based practices in online learning: A meta-analysis and review of online learning studies. Washington, D.C.: U.S. Department of Education, Office of Planning, Evaluation, and Policy Development.

Mursion. (2018). Research base for virtual reality simulations for learning. Retrieved from https://mursion.com/research.html

Patton, M. Q. (2002). Qualitative research \& evaluation methods (3rd ed.). Thousand Oaks, CA: Sage.

Putman, S., Ford, K., \& Tancock, S. (2012). Redefining online discussions: Using participant stances to promote collaboration and cognitive engagement. International Journal of Teaching \& Learning in Higher Education, 24(2), 151-167.

Straub, C., Dieker, L., Hynes, M., \& Hughes, C. (2014). TeachLive national research project. Retrieved 12, 2014 from http://teachlive.org/wp-content/uploads/2014/ 10/2014_GR_Technical_Report_10_20_FINAL.pdf.

Zhao, Y., Lei, J., Yan, B., Lai C., \& Tan, H. S. (2005). What makes the difference? A practical analysis of research on the effectiveness of distance education. Teachers College Record, 107(8), 1836-1884. 